\title{
Mali Dengeler ile CDS Primleri Arasındaki Nedensellik İliş̧kisinin Analizine Yönelik Bir Çalışma; Türkiye Örneği*
}

\author{
Esra N. KILCI*
}

\section{Öz}

2010-2014 döneminde Avrupa Bölgesi'nde yașanan borç krizinde temel faktörlerden biri, finansal stres yaşayan Yunanistan, İspanya ve Portekiz gibi ülkelerin makroekonomik temellerindeki dengesizliklerdir. Kriz döneminde, makroekonomik göstergelerdeki sıkıntılar, küresel yatırımcı algısının bozulması ve risk primindeki artışla birlikte, söz konusu ülke CDS (kredi temerrüt swap) primlerinin belirgin şekilde yükselmesine yol açmış; uygulanan tasarruf programlarına rağmen, CDS primleri yüksek seviyelerini bir süre korumuștur. Bu çalıșmanın amacı, Türkiye'de, mali dengeye ișaret eden bütçe açığı/GSYIH ve cari açık/GSYIH oranları ile ülke CDS primleri arasındaki ilișkinin 2006:Ç1-2018:Ç3 dönemi verileri kullanılarak analiz edilmesidir. Türkiye İstatistik Kurumu Veritabanı'ndan ve Bloomberg'ten elde edilen çeyrek dönem verileriyle yapılan analizde, Fourier ADF birimkök testi ve Fourier Granger nedensellik testi kullanılmıştır. Bu testler, çok sayıda yapısal kırılmanın analizde dikkate alınmasına olanak sağlayarak, sonuçların güvenirliğinin artmasına katkıda bulunmaktadır. Çalıșma sonuçları, Türkiye'de, 2006:Ç1-2018:Ç3 döneminde cari açık/GSYİH oranı ile CDS primleri arasında bir nedensellik ilişkisi olduğuna işaret etmektedir. Buna göre, söz konusu dönemde, mali dengeye indikatörlerinden olan cari açı/GSYIH oranı, CDS primleri üzerinde kısa dönemde etkiye sahip bulunmaktadır.

Anahtar Kelimeler: Bütçe Açığı, Cari Açık, Mali Denge, Ülke CDS Primleri, Yapısal Kırılmalar

Jel Kodları: E62, E66, H60

\author{
Özgün Araştırma Makalesi (Original Research Article) \\ Geliş/Received: 27.08.2019 \\ Kabul/Accepted: 25.10 .2019 \\ DOI: http://dx.doi.org/10.17336/igusbd.611970
}

* Bu çalışma, 17-19 Nisan 2019 tarihlerinde İstanbul'da düzenlenen GELIŞ̦íM-UWE 2019: 3. Uluslararası Ekonomi, Finans ve Yönetim Konferansı'nda sunulan "Mali Dengeler ile CDS Primleri Arasındaki Nedensellik İlişkisinin Analizine Yönelik Bir Çalıșma; Türkiye Örneği” isimli sözlü bildirinin genișletilmiș ve revize edilmiș halidir.

${ }^{* *}$ Dr. Öğr. Üyesi, İstanbul Arel Üniversitesi, İ.İ.B.F., Uluslararası Ticaret ve Finans Bölümü, İstanbul, Türkiye, E-posta: esrakilci@arel.edu.tr, ORCID ID https://orcid.org/0000-0002-2239-4560 


\title{
A Study on Analysis of the Causality Relationship between Fiscal Balance and CDS Premiums; Evidence from Turkey
}

\begin{abstract}
One of the major factors in the debt crisis in Euro-Area experienced over the period of 2010-2014 is the macroeconomic imbalances of the countries under financial stress such as Greece, Spain and Portugal. In the crisis period, the CDS (credit default swap) premiums of these countries increased significantly due to the weakening macroeconomic indicators, the deterioration in the global investor perception and the increase in the risk premium. Despite the austerity programs implemented, CDS premiums stayed in high levels for a period. The objective of this study to investigate the relationship between fiscal balances as budget deficit to GDP ratio and current account deficit to GDP ratio and sovereign CDS premiums in the period of 2006:Q1-2018:Q3. In the analysis, Fourier ADF unit root test and Fourier Granger causality test are employed by using the quarterly data obtained from TurkSTAT Statistics Database and Bloomberg. These test allow for taking into account multiple structural breaks in the analysis, contributing to credibility of the results. The results supported the causality relationship from current account to GDP ratio to sovereign CDS premiums for the period of 2006:Q1-2018:Q3 in Turkey. Accordingly, it is seen that current account to GDP ratio, one of the indicators of fiscal balance, has impact on CDS premiums in the relevant period.
\end{abstract}

Keywords: Budget Deficit, Current Account Deficit, Fiscal Balance, SCDS Premiums, Structural Breaks

JEL Codes: E62, E66, H60

\section{Giriş}

CDS primlerinde değişimlere yol açan faktörleri konu alan çalışmaların bir kısmında, hisse senedi piyasası, bankacılık sektörü göstergeleri veya politik risk gibi unsurlar ele alınmakta iken; bazı çalıșmalarda da, ekonomik büyüme oranı, döviz kurları, faiz oranları, cari açık, enflasyon ve işsizlik oranı, kamu borcunun GSYH'ye oranı gibi makroekonomik değișkenlere odaklanıldığı görülmektedir. Özellikle, 2010-2014 döneminde yaşanan Avrupa Borç Krizi ile birlikte, mali göstergelerin tahvil-bono marjları ve CDS primleri üzerine etkileri konusu, araştırmacılar, politika yapıcılar ve yabancı yatırımcılar açısından önemle dikkate alınmaktadır. Çünkü makroekonomik görünümdeki kötüleşme ve mali riskler, yatırımcı algısında bozulmaya yol açmakta ve ülke risk priminde artışla sonuçlanmaktadır.

Avrupa Borç Krizi, 2009 yllı sonunda, Yunanistan'ın 2009 yılı bütçe açığının GSYİH'ya oranının, ki anons edilen son dönem verisi \%6 seviyesinde idi, \%14'e revize edildiğini açıklamasının ardından başlamıştır. $\mathrm{Bu}$ durum, ülkenin borçlarının sürdürülebilirliği ile ilgili endișeleri arttırarak, ülke tahvil faiz oranlarının şiddetli bir şekilde yükselmesine yol açmıştır. İlerleyen dönemde, İspanya ve Portekiz gibi diğer bazı ülkelerde de benzer sıkıntıların var olduğu ortaya çıkmıştır (Neri ve Ropele, 2015). Kriz daha sonra İtalya, İzlanda ve İrlanda gibi diğer Avrupa ülkelerinde etkisini göstermiştir. İrlanda ve İspanya'da hükümet, özel sektörün borçlarını üstlenerek bankaların sorunlarını hafifletmeye çalışmıştır. Borç krizinin yaşandığı ülkelerin devlet borçlanmalarında hızlı artışlar gözlemlenmiştir. 2008 yılında brüt kamu borçlarının 
GSYİH'ya oranı, Yunanistan için \%122.5, İtalya için \%118.9, İzlanda için \%76.4, İrlanda için \%50.1 ve İspanya için \%48 iken; 2011 yılının sonunda bu oran, Yunanistan için \%179.9, İtalya için \%124.0, İzlanda için \%106.8, İrlanda için \%103.9 ve İspanya için \%78.8 olmuştur. Devlet borçlanmalarındaki hızlı artışlar, finansal piyasalarda, sözkonusu borçlar nedeniyle artan temerrüt riskinden korunmak için, CDS piyasasına daha fazla başvurulmasına yol açmıştır (Yüksel ve Yüksel, 2017).

Avrupa Borç Krizi'nde, yapısal reformları erteleyen, Birlik içerisinde yer alan ülkelerin mali göstergelere ilișkin uymaları gereken kriterleri göz ardı eden ve düșük faiz oranları ile kamu ve özel sektör borçlanmasını aşırı yüksek seviyelere çıkartan Yunanistan, İrlanda, İspanya, İtalya ve Portekiz gibi ülkeler, borç yükümlülüklerini yerine getirebilmek için, Avrupa Birliği ve IMF'ten destek almak durumunda kalmışlardır. Yüksek kamu borcu ve mali açıklar, ülkelerin kamu maliyelerinin sağlamlığı ve borçlarının sürdürülebilirliği konusunda soru işaretlerini beraberinde getirmiştir. Bütçe açıklarını azaltmak ve mali sağlamlığı yeniden tesis edebilmek amacıyla, söz konusu ülkeler, geniş ölçekli tasarruf tedbirlerini uygulamaya koymuşlardır. Finansal stres altındaki ülkeler, mali açık hedefleri açısından olumsuz bir performans sergilemişlerdir ve söz konusu açıkları iyileștirebilmek amacıyla, mali sıkılaştırma uygulamalarına rağmen, CDS primleri, yüksek seviyelerini korumuştur. $\mathrm{Bu}$ ülkelerde, olumsuz makroekonomik görünüm, yüksek CDS primlerine yol açan majör faktörlerden olmuştur.

Oliverira ve diğ. (2012), Avrupa Borç Krizi'nde finansal piyasaların, ülkelerin mali ve makroekonomik dengesizliklerini ağır bir şekilde cezalandırdığını ve bu dengesizliklerin uluslararası risk faktörüyle etkileșiminin fiyatlandırıldığını vurgulamışlardır. Ülke makroekonomik temellerindeki bozulmalar, yüksek bütçe açıkları ve cari açıklar, finansal piyasalarda fiyatlandırılmış ve ülke tahvil-bono marjları ve CDS primlerinin belirgin şekilde artmasına yol açmıştır. Yuan ve Pongsiri (2015), Avrupa Borç Krizi'nde açıkça görülen, mali dengesizlikler ve CDS primleri arasındaki ilişkiden hareketle, tasarruf uygulamaları ve mali dengenin sağlanmasına yönelik çözümlerin, genellikle bir ülkenin mali görünümünün iyileşmesine katkıda bulunarak, borçlu ülkelerin borcunu ödeyebilme gücünün göstergesi olan CDS primlerine olumlu etkide bulunacağını belirtmektedir.

Nickel ve diğ. (2009), gelişmekte olan ülkelerde politika yapıcılarının, mali dengeyi sağlamak konusunda ihtiyatlı olmaları gerektiğine işaret etmektedir. Ekonomik kalkınma ve finansal piyasalar arasındaki yüksek entegrasyon, finansal oyuncuların analizlerinde, mali denge ve güçlü maliyet politikalarının varlığını dikkate almaları sonucunu doğurmaktadır. Bu doğrultuda, örneğin, 2008 yılında Macaristan'da yaşanan finansal kriz ve 2010-14 döneminde Avrupa Bögesi'nde yaşanan borç krizinde görüldüğü üzere, yüksek mali açlklar ve borç seviyeleri, ülke finansal piyasalarında kırılganlığın artmasına neden olmaktadır. Ayrıca, yapılan çalışmalar, mali dengeye ilișkin göstergelerin, tahvil-bono marjları ve CDS primleri üzerindeki etkilerinin büyük ölçüde, ülkelerin gelişmişlik düzeyi ve finansal piyasa koșullarına bağımlı olarak farklılık arzettiğini göstermektedir.

Bu çalışmada ilk odak noktamız, mali denge indikatörlerinden bütçe açı̆̆ı/GSYïH oranı ile CDS primleri arasındaki ilişkidir. Türkiye, 2001 Ekonomik Krizi sonrası dönemde uygulanan mali disiplin sonucunda, kriz öncesi dönemde $\% 12$ seviyesindeki bütçe açığı/GSYIH oranını ve \%40 seviyesindeki kamu borcu/GSYIH oranını ılımlı seviyelere indirmeyi başarmıştır. Söz konusu açıklar, yurtiçi tasarruflarda azalmaya, enflasyon ve faiz oranlarında artışa yol açmaktaydı. 2000'li yılların en önemli özelliklerinden birisi, 1990'lı yıllar ile karş̧laştırıldığında, makroekonomik performansta görülen olumlu ivmedir. Pek çok makroekonomik gösterge, 1990’lı yıllara göre oldukça önemli ve olumlu bir gelişme kaydetmiş̦tir. Enflasyon oranı, bütçe 
açı̆̆ı/GSYIH oranı, kamu kesimi borçlanma gereği, kamu borcu/GSYİH oranı gibi temel mali göstergelerde iyileşme sağlanmıștır. Merkezi yönetim bütçe açığının ve kamu borcunun GSYIHH'ya oranı ciddi bir şekilde düşmüştür. Türkiye'de bütçe açı̆̆ı/GSYïH oranı, 2000 yılında \%-7,9 iken, 2002 yılında \%-11,5’e kadar yükselmiş, 2007 yılında \%1,6, 2011 yılında \%-1,4 ve 2014 yılında \%-1,3 olmuștur. Aynı șekilde, kamu borcu/GSYIH oranı, 2002 yılında \%74 iken, 2007 yılında \%39,9, 2011 yılında \%39,1 ve 2014 yılında \%37,2'ye kadar gerilemiştir (Sungur, 2015). 2017 yllında ise bütçe açığı/GSYIH oranı, \%-1,5 seviyesindedir (TÜİK, 2019). Türkiye'de, A.B üye ülkeleri ve aday ülkeleri için GSYIH'ya oranı azami \%3 olan bütçe açığı Maastricht Kriteri'nin fazlasıyla sağlandığı görülmektedir.

Bununla beraber, cari açı̆̆ın, özellikle 2005 yılı sonrası dönemde, parasal değer ve GSYİH'ya oran olarak belirgin şekilde arttığı görülmektedir. Cari açı/GSYIH oranı, 2011 yılında, \%10'a yakın bir değerle, tarihi zirve değerini görmüștür ve 2017 yılı itibariyle, söz konusu oran \%-5,5 seviyesindedir (TÜIK, 2019). Türkiye, Brezilya, Arjantin ve Hindistan gibi diğer gelişmekte olan ülke ekonomileri ile birlikte yüksek cari açık veren ülkelerden biridir ve bu açığı ağırlıklı olarak dış borçlanmayla finanse etmektedir. Türkiye'de, 2018 yılında, politik risteki artış ve buna paralel olarak döviz kurlarında Türk Lirası aleyhine belirgin bir değerlenme yaşanmış olup; bu değerlenmenin 2018 yılı cari işlemler dengesine olumlu katkı yapması beklenmektedir. Nitekim, 2018 yılı Ağustos ayı itibariyle, TCMB tarafından açıklanan veriye göre, Türkiye, 2015 yılından itibaren ilk defa cari fazla vermiștir. 2017 yılı Ağustos ayında 923 milyon dolar açık veren cari işlemler hesabı, 2018 yılı Ağustos ayında 2 milyar 592 milyon dolar fazla vermiştir (TCMB, 2019).

$\mathrm{Bu}$ çalıșmanın amacı, mali dengenin görünümüne ilişkin indikatörler olarak bütçe açı̆̆ı/GSYİH oranı ve cari açık/GSYİH oranı ile 5 yıllık ülke CDS primleri arasındaki ilişkinin analiz edilerek, 2006:Ç1-2018:Ç3 döneminde, mali dengeye ilișkin indikatörlerin CDS primlerinin açıklanmasında etkisi olup olmadığının araştırılmasıdır. Çalışmada, değişkenlerin durağanlıklarının test edilmesi amacıyla, Fourier ADF birim kök testi ve değişkenler arasındaki nedensellik ilişkisinin test edilmesi amacıyla, Fourier Granger nedensellik testi uygulanmaktadır. Fourier ADF birim kök testi, birden fazla yapısal değișimin düșük frekanslı Fourier fonksiyonlarıyla tahmin edilmesine olanak sağlamaktadır. Diğer birçok yöntemin aksine, yapısal değişimin sayı ve konumunu bilmek zorunluluğu ortadan kalkmaktadır. İzleyen aşamada kullanılan Fourier Granger nedensellik testinde esnek Fourier formu kullanılarak, VAR sistemi içerisinde var olan yumuşak kırılmalar yakalanmaya çalışılmaktadır. Bu testlerin kullanılmasıyla, analiz sonuçlarının güvenilirliği arttırılmaya çalıșılmaktadır. Çalıșma aşağıdaki şekilde ilerlemektedir; 2. Bölüm'de literatür araştırması kapsamında CDS primleri ile makro göstergeler arasındaki ilişkiyi inceleyen çalışmalar özetlenmektedir. 3. Bölüm'de analizde kullanılan veri seti ve yöntem açıklanmakta; 4. Bölüm'de analiz sonuçları sunulmakta ve 5. Bölüm'de yer alan sonuç kısmıyla çalışmaya ilişkin genel bir değerlendirme yapılarak çalıșma sonlandırılmaktadır.

\section{Literatür Araştırması}

Temerrüt riskinin ve borçlanma maliyetlerinin arttığına işaret eden CDS primlerindeki artışlar, finansal stres yaşayan ülkelerin yatırım yapılabilirliği ile ilgili endişeleri beraberinde getirmekte, bankacılık sektöründeki problemler, küresel risk algısındaki değişimler, politik risklerdeki artışlar gibi faktörlerin yanı sıra, ülke makroekonomik görünümündeki bir bozulmanın sonucunda da yukarı yönlü bir trende sahip olabilmektedir. Așağıda, akademik literatürde makroekonomik temeller ve mali 
dengesizlikler ile CDS primleri arasındaki ilişkiyi araştıran çalışmalara kısaca yer verilmektedir.

Nickel ve diğ. (2009), mali göstergelerin tahvil-bono marjları üzerindeki etkilerini, Çekya, Macaristan, Polonya, Rusya ve Türkiye için, 1998:05-2007:12 döneminde araștırmıșlar; mali göstergeleri de kapsayan açıklayıcı değișkenlerin tahvilbono primleri üzerinde etkili olduğunu bulmuşlardır. Buna göre, özelikle, mali açlk oranı, neredeyse tüm ülkelerde tahvil-bono marjları üzerinde güçlü ve anlamlı bir etkiye sahiptir. Dolayısıyla, Nickel ve diğ. (2009), gelişmekte olan ülke ekonomilerinde politika yapıcıların, mali dengelerin yönetiminde ihtiyatlı olması gerekliliğinin altını çizmektedirler. Liu ve Morley (2013), 2004:01-2010:02 döneminde, A.B ülkeleri, A.B.D ve Japonya'da, makroekonomik göstergeler, kredi derecelendirme notları ve CDS primlerine odaklanarak, ülke CDS primlerini etkileyen majör faktörleri incelemişler; kredi derecelendirme notları ve CDS primleri arasında herhangi bir ilişkinin olmadığını bulmuşlar; bununla beraber, bir ekonominin sağlamlığına işaret eden makroekonomik göstergelerin, ülke CDS primlerini etkileyen temel değişkenler olduğunu tespit etmişlerdir.

Kliber (2014), 2008-2011 döneminde, stokastik volatilite modellerini kullanarak ve Çekya, Macaristan ve Polonya'nın CDS primlerine odaklanarak, CDS primlerini etkileyen dinamikleri incelemiş; Macaristan ve Yunanistan'da yaşanan mali dengesizliklerin, analize konu olan ülke CDS primlerinde etkili olduğu sonucuna ulaşmıştır. Oliveira ve diğ. (2012), 2000:01-2010:12 döneminde Euro cinsinden ihraç edilen devlet tahvillerine ait veri setini kullanarak ve analiz dönemini 2007 öncesi ve sonrası şeklinde iki döneme ayırarak, Euro-Bölgesi'nde ülke CDS primlerini etkileyen faktörleri incelemişler; 2007 öncesi dönemde, piyasalara ilişkin faktörlerin ülke CDS primleri üzerinde etkili olduğunu; 2007 sonrası dönemde ise finansal stresin ve ülkeye özgü makroekonomik faktörlerin belirleyici önem kazandığını vurgulamışlardır.

Heinz ve Sun (2014), 2007:01-2012:12 dönemi verilerini GLS hata düzeltme modeli çerçevesinde analiz ederek, Euro-Bölgesi ülke CDS primlerinin, küresel yatırımcı algısı, makroekonomik temeller ve CDS piyasasındaki likidite koşulları tarafından etkilendiğini; bununla beraber, bu faktörlerin göreceli öneminin zaman içerisinde değiştiğini bulmuşlardır. 2008-09 Küresel Finansal Krizi'nde, yüksek cari açı, yüksek bütçe açıkları ve borç seviyeleri, kredi büyümesi, zayıf ekonomik temeller, likiditede yaşanan azalma ve riskten kaçınma davranışı, bazı Avrupa ülkelerinde yüksek CDS primlerine katkıda bulunmuştur. Analiz sonuçları, CESEE ülkelerinin (Orta, Doğu ve Güneydoğu Avrupa ülkeleri) makroekonomik temellerindeki (bütçe açı̆̆ı ve cari açıktaki azalma ile büyümedeki artış) iyileşmelerin, bu ülkelerin CDS primlerinin Avrupa Borç Krizi'nden daha az etkilenmesindeki önemli nedenlerden biri olduğunu göstermektedir. Buna göre, söz konusu ülkelerin CDS primleri, mali ve cari dengelerindeki iyileşme neticesinde, 2008-09 Küresel Finansal Kriz dönemi ile karşılaştırıldığında, kısmen az etkilenmiştir.

Clark ve Kassimatis (2015) gelişmekte olan ülke ekonomilerinde, ülke CDS primlerindeki değiş̧imlerin açıklanmasında, makroekonomik temellerin rolünü incelemişlerdir. Bu ülkelerde CDS primlerinin gelecek dönem performansına yönelik yatırımcı beklentilerini yansıtan piyasa değerleriyle ilgili makroekonomik değișkenlere odaklanarak yaptıkları analiz sonucunda, makroekonomik değișkenlerdeki iyileșmenin CDS primlerinin azalmasına katkıda bulunurken, finansal riskteki artışın ise CDS primlerinin artmasına yol açtığını tespit etmişlerdir. Ayrıca, ülkenin getiri oranı ve döviz kuru arasındaki yüksek korelasyon, primlerin düşmesine katkıda bulunmaktadır. Yuan ve Pongsiri (2015), Euro-Bölgesi ülkelerinin de içerisinde olduğu 36 ülke için, mali sıkılaştırma, büyüme beklentileri ve diğer makroekonomik göstergelerin ülke CDS primleri fiyatlamasındaki etkisini analiz etmiş; mali sıkılaştırma uygulamalarının 
genellikle mali durumun güçleneceğine ilişkin beklentileri arttırarak, CDS piyasası üzerinde olumlu etkide bulunduğunu; kamu borcu/GSYİH oranı ve gelecekte beklenen büyüme artışının CDS primlerinin belirlenmesinde önemli bir role sahip olduğunu belirtmișlerdir.

Schwaab ve diğ. (2016), dinamik hiyerarşik faktör modelini kullanarak, 2008-09 Küresel Finansal Kriz ve 2010-2014 Avrupa Borç Krizi'ni kapsayan 1980-2014 döneminde, ülkeler, endüstriler ve derecelendirme kuruluşları için, sistemik temerrüt riski koşullarının belirleyici özelliklerini araștırmışlar; makroekonomik ve temerrüde özgü küresel faktörlerin, ülkelerde temerrüt riskinin temel kaynakları olduğu sonucuna ulaşmışlardır. Filippos (2017), 2010:01-2016:12 döneminde, 15 Euro-Bölgesi ülkesi için, enflasyon oranı, reel kur endeksi, borç/GSYIH oranı, borç/ihracat oranı, ekonomik büyüme oranı, rezerv/borç oranı, cari açık oranı ve risk iștahı gibi makro-finansal faktörlerin CDS primleri üzerindeki etkisini ve aynı zamanda, CDS primlerinin alternatif bir kredi riski ölçüm aracı olarak kullanılıp kullanılamayacağını test etmiş; enflasyon oranı, cari açık oranı, rezerv/borç oranı, risksiz faiz oranı ve reel kur endeksi gibi değişkenlerin CDS primleri üzerinde hem istatistiki hem ekonomik anlamda güçlü şekilde etkili olduğu ve aynı zamanda CDS primlerinin kredi riskinin ölçülmesinde kullanılabileceği sonucuna ulaşmıștır.

Cepni ve diğ. (2017), sekiz gelișmekte olan ülke ekonomisine ait 2005-2015 dönemi verilerinden yararlanarak ve sabit etki panel regresyon analizini kullanarak, gelişmekte olan ülke ekonomilerinde, makroekonomik faktörlerin, ülke CDS primlerinin küresel risk iştahındaki değişime olan duyarlılığını açıklamakta oynadığı rolü analiz etmişler; kamu borcu/GSYİH ve brüt rezervler/GSYİH oranlarının, CDS primlerinin duyarlılığını açıklamakta en önemli faktörler olduğunu bulmuşlardır. Buna göre, düșük kamu borcu ve yüksek döviz rezervlerine sahip ülkeler, küresel risk iștahındaki değişimlere daha az maruz kalmaktadır. Dolayısıyla, ülkelerin borç miktarını azaltmaya yönelik politikalar ve döviz rezervlerinin artmasını sağlayacak adımlar, risk faktörlerine karșı duyarlılığı azaltmaktadır. Ayrıca, analiz sonuçları, risk faktörlerine olan duyarlılığın, fiyat istikrarı ve finansal istikrar açısından önemli etkileri olduğuna işaret etmişstir.

\section{Ekonometrik Uygulama 3.1 Veri ve Yöntem}

Çalışmada, bütçe açı̆̆ı/GSYİH ve cari açı/GSYIH oranları ile CDS primleri (5 yıllık) arasındaki nedensellik ilișkisi Fourier yaklașımı kullanılarak analiz edilmiștir. Analizde, 2008-09 Küresel Finansal Krizi ve 2010-14 Avrupa Borç Krizi ve Türkiye'de politik riskin belirgin șekilde arttı̆̆ı, döviz kurunda Türk Lirası aleyhine aşırı değerlenmenin yaşandığı ve makroekonomik indikatörlerde kısmi bir kötüleşme yaşandığı 2016-2018 zaman aralığını kapsayan 2006:Ç1-2018:Ç3 dönemi verileri kullanılmaktadır. Söz konusu göstergelere ilișkin veriler, Türkiye İstatistik Kurumu İstatistik Veri Tabanı'ndan ve Bloomberg'den elde edilmiștir. 


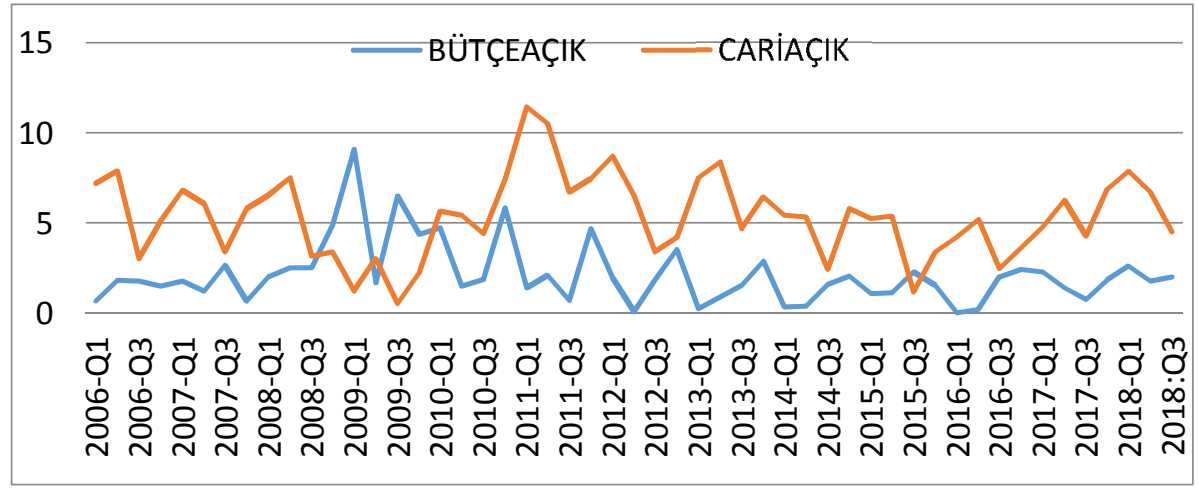

Kaynak: TÜİK İstatistik Veri Tabanı

Grafik 1: Bütçe açı̆̆ı/GSYİH ve Cari açı/GSYİH oranları, 2006-2018

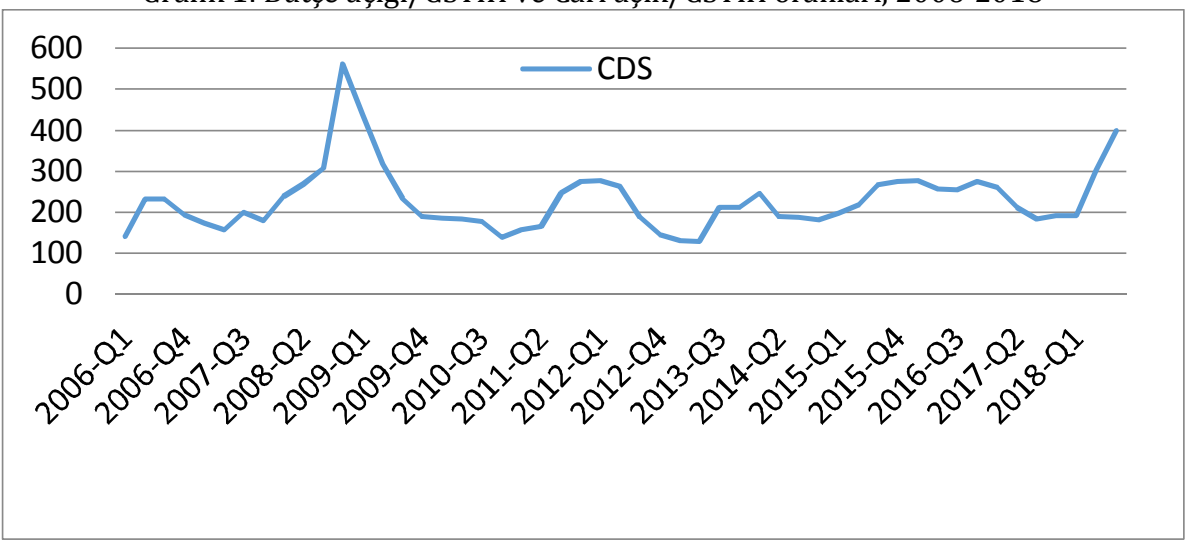

Kaynak: Bloomberg

Grafik 2: CDS Primleri, 2006-2018

Grafik 1 ve 2 sırasıyla, bütçe açı̆̆ı ve cari açı̆̆ın GSYH'ye oranlarının ve CDS primlerinin 2006:Ç1-2018:Ç3 döneminde aldığı değerleri göstermektedir. Așağıdaki tabloda, analizde kullanılan bağımlı-bağımsız değișkenlere ve söz konusu değişkenlerin kısaltmaları ile değişkenler arasında beklenen ilişkiye yer verilmiștir. Bu doğrultuda, bağımlı değișken olarak 5 yıllık CDS primleri ve bağımsız değişken olarak bütçe açığı/GSYIH ve cari açık/GSYİH oranları arasındaki ilişski analiz edilmeye çalışılmıştır.

\begin{tabular}{llll}
\hline & Değişkenler & Kısaltma & Beklenen Etki \\
\hline Bağımlı Değişken & 5 yıllık CDS Primleri & CDSPRIM & $(+)$ \\
Bağımsız Değişken & Bütçe açı̆̆ı/GSYIH oran & BÜTÇEAÇıK & $(+)$ \\
Bağımsız Değişken & Cari açık/GSYiH oranı & CARİAÇIK & $(+)$ \\
\hline
\end{tabular}

Tablo 1: Uygulamada Kullanılan Bağımlı ve Bağımsız Değișkenler 
$\mathrm{Bu}$ çalışmada, mali denge indikatörlerinden bütçe açı̆̆ı/GSYIH ve cari açı/GSYIH oranları ile CDS primleri arasındaki nedensellik ilişkisi, Fourier Granger nedensellik testi yardımıyla incelenmektedir. Öncelikle, serilerdeki durağanlığın düzeyini belirlemek amacıyla birim kök testi yapılmaktadır. Ekonomik zaman serilerinin durağanlı̆̆ının test edilmesi büyük öneme sahiptir. Bu nedenle, öncelikle, ADF ve Fourier ADF yardımıyla serilerin durağanlığı test edilmektedir. Çalışmada Fourier ADF birim kök testi kullanılmasının amacı, bu yöntemin birden fazla yapısal değișimin düșük frekanslı Fourier fonksiyonlarıyla tahmin edilmesine olanak sağlamasıdır. Diğer birçok yöntemin aksine, yapısal değişimin sayı ve konumunu bilmek zorunluluğu ortadan kalkmaktadır. İzleyen aşamada ise, değişkenler arasındaki nedensellik ilişkisinin araştırılması amacıyla Fourier Granger nedensellik testine başvurulmaktadır. Değișkenler arasındaki bağlantılar, yapısal kırılmalara maruz kaldığı ve aynı zamanda doğrusal spesifikasyonlar bu ilişkileri yakalamakta çoğu zaman yetersiz kaldığı için, ekonometrik analizlerin karmaşık hale geldiği görülmektedir. Bu doğrultuda, Fourier Granger nedensellik testinde esnek Fourier formu kullanılarak, VAR sistemi içerisinde var olan yumuşak kırılmalar yakalanmaya çalışılmaktadır.

\subsection{Analiz ve Sonuçlar}

Enders ve Lee (2012), çalışmalarında, bir veya daha fazla yapısal değișmenin düşük frekanslı Fourier fonksiyonlarıyla tahmin edilebileceğini belirtmektedir. Fourier ADF birim kök testinin uygulanması sırasında, yapısal değişimin konum ve sayısından ziyade, Fourier fonksiyonunun uygun frekans sayısının bilinmesi önem taşımaktadır. Testin ilk aşamasında aşağıdaki model tahmin edilmektedir:

$$
\Delta \mathrm{y}_{\mathrm{t}}=\rho \mathrm{y}_{\mathrm{t}-1}+\beta_{1}+\beta_{2} \text { trend }+\beta_{3} \sin (2 \pi k t / T)+\beta_{4} \cos (2 \pi k t / T)+\mathrm{ut}_{\mathrm{t}}
$$

Burada t trendi, $\mathrm{T}$ örneklem sayısını ve $\pi=3.1416$ 'yı ifade etmekte olup; k'nın optimal değerini bulabilmek için, k yerine 1-5 aralığındaki değerler kullanılıp model tahmin edilmekte ve en küçük KKT'yi veren k'ya ulaşılmaya çalışılmaktadır. Uygun olduğu tespit edilen k'nın olduğu modelde, otokorelasyon sorunu olması halinde, bağımlı değișkenin gecikmeli değerleri modele dâhil edilmektedir. Serinin durağan çıkması halinde ise, trigonometrik terimlerin anlamlılığını sınamak için $\mathrm{F}$ testi kullanılmaktadır.

$\beta_{3}=\beta_{4}=0$

Uygun kritik değerler, Enders ve Lee (2012) makalesinde yer almaktadır. 


\begin{tabular}{|c|c|c|c|c|c|c|}
\hline Seriler & Frekans & MinKKT & \multicolumn{2}{|l|}{ Fourier ADF } & ADF t-istatistiği & F-istatistiği \\
\hline CDSPRIMM & 5 & 125210.9 & $-2,704611^{* * *}$ & & $-3,256634^{* *}$ & 5,961946 \\
\hline BÜTÇEAÇIK & 1 & 0.018564 & $-6,016710^{*}$ & & $-2,672381^{* * *}$ & 2,219538 \\
\hline CARİAÇIK & 2 & 0.027309 & $-4,897313^{*}$ & & $-3,806534^{*}$ & 1,482683 \\
\hline \multicolumn{3}{|c|}{$\begin{array}{l}\text { ADF Kritik Değer } \\
\text { FADF F-istatistiği Kritik Değer } \\
\end{array}$} & \multicolumn{3}{|c|}{ Fourier ADF Kritik Değer $(5,1,2)$} & \\
\hline$\% 1\left(^{*}\right)$ & & & $-3,58$ & $-4,42$ & $-3,97$ & \\
\hline $\begin{array}{l}\% 5(* *) \\
7,58\end{array}$ & & & $-2,93$ & $-3,81$ & $-3,27$ & \\
\hline $\begin{array}{l}\% 10(* * *) \\
6,35\end{array}$ & & & $-2,60$ & $-3,49$ & $-2,91$ & \\
\hline
\end{tabular}

Tablo 2: ADF ve Fourier ADF Birim Kök Test Sonuçları

Test sonuçlarına göre, serilerin I(0) seviyesinde durağan oldukları görülmektedir. Bununla beraber, F-istatistikleri, aynı çalışmada geçen F-istatistikleri ile karşılaştırılarak, trigonometrik değerlerin anlamlılığı sınandığında, trigonometrik değerlerin anlamlı olmadığı görülmüștür. Bu nedenle, ADF testi uygulanmış ve tüm değişkenlerin durağan olduğu bulunmuştur.

İzleyen aşamada, Enders ve Jones (2016) tarafından geliştirilen Fourier Granger nedensellik testi yapılarak, değişkenler arasında bir nedensellik ilișkisinin olup olmadığı araştırılmaktadır. Değișkenler arasındaki bağlantılar, yapısal kırılmalara maruz kaldığı ve aynı zamanda lineer spesifikasyonlar, bu ilişkileri yakalamakta çoğu zaman yetersiz kaldığı için, ekonometrik analizlerin karmaşık hale geldiği görülmektedir. Ender ve Jones (2016), esnek Fourier formu kullanarak, VAR sistemi içerisinde var olan yumuşak kırılmaları yakalamaya çalışmışlar ve Granger nedensellik testlerini kullanarak kısa dönemli dinamikler üzerine yoğunlaşmışlardır.

Kırılmaların sayısını, oluşumunu ve büyüklüğünü tahmin etmek yerine, Enders ve Jones (2016) VAR sisteminde var olan kırılmaları kontrol etmek için esnek Fourier formu denemişler ve değișkenlerin durağanlığını test ettikten sonra, doğrusal VAR denklemini aşağıdaki şekilde tanımlamışlardır:

$$
z_{t}=\delta+\sum_{i=1}^{11} A_{i} z_{t-i}+e_{t}
$$

Burada, $\delta$, sabit terimlerin $(4 \times 1)$ bir vektörü olup; $A_{i},(4 \times 4)$ vektör katsayısı ve $e_{t}$ ise değişikliklerin bir vektörüdür. Bununla beraber, iki nedenle problemli sonuçlar ortaya çıkabilmektedir. Farkedilmeyen yapısal değişimler nedeniyle, (3) numaralı denklem yanlış tanımlanmış olabilmekte ve aynı zamanda, denklemdeki güven aralıkları gereksiz şekilde geniş tanımlanabilmektedir. Dolayısıyla, Enders ve Jones (2016), (3) numaralı VAR denkleminin yerine, deterministik regresörleri aşağıdaki șekilde belirlemişlerdir:

$$
\begin{aligned}
& z_{t}=\delta(t)+\sum_{i=1}^{11} A_{i} z_{t-i}+e_{t} \\
& \delta(t)=\left[\delta_{1}(t), \delta_{2}(t), \delta_{3}(t), \delta_{4}(t)\right]^{\prime}
\end{aligned}
$$

ve her sabit $\delta_{i t}$ aşağıdaki șekilde $\mathrm{n}$ tane Fourier frekansına bağlı olmaktadır: 


$$
\delta_{i}(t)=a_{i}+b_{i} t+\sum_{k=1}^{n} a_{i k} \sin \left(\frac{2 \pi k t}{T}\right)+b_{i k} \cos \left(\frac{2 \pi k t}{T}\right)
$$

Kırılmaların kontrol edilmesinde Fourier terimleri kullanıldığı zaman, Granger nedensellik testleri, daha önce elde edilen sonuçlardan önemli ölçüde farklılaşmaktadır. Enders ve Jones (2016) modele trigonometrik fonksiyonları ekleyerek, değişkenler arasında çok daha güçlü ilişkiler tespit etmişlerdir.

\begin{tabular}{llllll}
\hline İlișki & & & Asymptotic & Bootstrap \\
optimal Frequency & Wald-stat & p-value & p-value & Optimal Lag \\
\hline CARİAÇIK-CDS & 2 & 3.724 & 0,445 & 0,452 & 4 \\
BÜTÇEAÇIK-CDS & 3 & 3.483 & 0,480 & 0,483 & 4 \\
CARİAÇIK-CDS & 3 & 16.401 & $0,003^{* *}$ & 0,008 & 4 \\
BÜTÇEAÇIK-CDS & 3 & 5.422 & 0,247 & 0,248 & 4 \\
\hline
\end{tabular}

Cari açık/GSYIH oranı $\rightarrow$ CDS primleri

Not: $\rightarrow$ nedenselliğe işaret etmektedir. Optimal k (frekans) ve $\mathrm{p}$ (gecikme) değerleri Akaike Bilgi Kriteri'ne göre belirlenmiștir. ${ }^{* *},{ }^{* *},{ }^{*}$ sirasıyla $\% 1, \% 5$ ve $\% 10$ istatistiki anlamlıllk düzeylerini göstermektedir. Bu çalışmada n(örneklem sayısı)>50 olduğu için, analizde asimptotik p değeri kullanılmaktadır.

Tablo 3: Fourier Granger Nedensellik Testi Sonuçları

Tablo 3'te, tek frekans ve kümülatif frekans için hesaplanan Fourier Granger nedensellik testi sonuçları yer almaktadır. Kümülatif frekans için hesaplanan değere göre, asimptotik p-değeri 0,05'ten küçük bir değer aldığı için, cari açık/GSYIH oranından CDS primlerine doğru bir nedensellik ilişkisi bulunmakta iken, bütçe açığı/GSYIH oranından CDS primlerine doğru bir nedensellik ilişkisinin bulunmadığı tespit edilmiştir. Buna göre, cari açık/GSYİH oranındaki değişimler, CDS primleri üzerinde kısa dönemde bir etkiye sahipken; bütçe açığı/GSYIH oranın CDS primleri üzerinde kısa dönemde bir etkisi bulunmamaktadır.

\section{Sonuç}

2010-2014 Avrupa Borç Krizi'nin ortaya çıkmasında ve derinleşmesinde, bölgede Yunanistan, İspanya, İtalya ve Portekiz gibi ülkelerin makroekonomik temellerindeki dengesizlikler önemli bir rol oynamıştır. Bu ülkelerin, özellikle mali açılklar ve borç oranları konusunda, A.B üye ülkelerin sağlamak zorunda oldukları Maastricht Kriterleri'ni sağlayamadığı görülmüş; finansal dalgalanma, bulaşma etkisiyle, stres altındaki ülkelerin problemlerinin, Avrupa Bölgesi içerisindeki diğer ülkelere yayılmasıyla, sistemik bir borç krizine dönüșmüş ve ülke temerrüt riskinin arttığına işaret eden ülke CDS primleri belirgin şekilde yükselmiştir. Özellikle, bu krizden yola çıkarak, akademik literatürde makroekonomik dengesizlikler ile CDS primleri arasındaki ilişkiyi konu olan çeşitli çalıșmalar yapılmıştır.

Türkiye'de 2001 Ekonomik Krizi sonrası dönemde, uygulanan mali disiplin ve yapısal reformlar neticesinde, makro-finansal indikatörlerde olumlu bir trend görülmüş; enflasyon ve ekonomik büyüme oranında yaşanan olumlu ivmenin yanı sıra, bütçe açığı ve kamu borcunun GSYH'ye oranı konusunda, birçok Avrupa ülkesinin aksine, Maastricht Kriterleri'nde belirlenen azami sınırların altında kalınmıștır. Bu çalıșmada, Türkiye'de 2006:Ç1-2018:Ç3 dönemi verileri esas alınarak ve Fourier Granger nedensellik testi kullanılarak, mali dengeyi gösteren indikatörlerden bütçe açı̆̆ı/GSYïH ve cari açık/GSYİH oranları ile Türkiye CDS primleri arasındaki nedensellik ilişkisi araştırılmıştır. Analiz sonuçları, bütçe açığı/GSYİH oranından CDS primlerine doğru bir 
nedensellik ilişkisinin bulunmadığını gösterirken; cari açı/GSYİH oranından CDS primlerine doğru bir nedensellik ilişkisinin varlığına işaret etmiştir.

Cari açık, sermaye girișleri devam ettiği sürece, gelișmekte olan ülke ekonomileri için sorun arz etmemektedir. Türkiye'nin de içinde bulunduğu gelişmekte olan ülke ekonomilerinde, yüksek cari açığın dış borçlanma ve portföy yatırımları şeklinde sermaye akımlarıyla finanse edildiği görülmektedir. Bununla beraber, finansal stresin arttığı dönemlerde, belirsizliğin artması, finansman maliyetlerinin artması ve olumsuz sermaye hareketlerinin görülmesi gibi nedenlerle, yüksek cari açlk oranları, ülke ekonomileri açısından sorun yaratmaktadır. Çünkü dış borçlanma maliyetleri artmakta ve borcun yenilenmesi konusunda problemlerle karşılaşılabilmektedir. Aynı zamanda, yabancı yatırımcılar, portföy yatırımlarını, daha güvenli ülkelere taşımayı tercih etmektedir. $\mathrm{Bu}$ nedenle, cari açığın kontrol altına alınmasına yönelik politikaların izlenmesi önemlidir. 2006-2016 dönemi incelendiğinde, cari açığın GSYH'ye oranı, 2009 yılındaki \%-1,8'lik değerinin dışında, neredeyse tüm yıllarda \%5 seviyelerinde seyretmiş; 2011 yılında ise, \%10'a yakın bir değer almıștır. 2017 yllı ve 2018 yılının ilk yarısında, güçlü iç talep, enerji fiyatlarındaki yükseliş nedeniyle, cari açık/GSYIH oranı yine yüksek seviyesini korumuştur.

Diğer yandan, 2018 yılı ikinci yarısından itibaren, döviz kurunda yaşanan değerlenme ve petrol fiyatlarında Eylül ayından itibaren görülen gerileme, cari açık/GSYİH oranının düşmesine olumlu katkıda bulunmuş; Türkiye Cumhuriyeti Merkez Bankası tarafından Ağustos 2018 dönemine ilişkin açıklanan ödemeler dengesi verilerine göre, geçen yılın Ağustos ayında 923 milyon dolar açık veren cari işlemler hesabı, 2018 yılının aynı ayında 2 milyar 592 milyon dolar fazla vermiştir. Dolayısıyla, 12 aylık cari işlemler açığı 51 milyar 125 milyon dolara gerilemiştir. Cari açık/GSYIH oranı ile CDS primleri arasındaki nedensellik ilişkisi dikkate alındığında, cari açıkta yaşanacak iyileşmenin temerrüt riskinin ve borçlanma maliyetlerinin arttığına işaret eden CDS primleri üzerinde olumlu etkisi olacağı düşünülmektedir. Özetlemek gerekirse, tasarruf uygulamaları ve mali dengenin sağlanmasına yönelik çözümlerle bütçe açığı ve cari açığın GSYH'ye oranında yaşanan iyileşmeler, bir ülkenin mali görünümünün iyileşmesine katkıda bulunarak, CDS primlerine olumlu etkide bulunmaktadır.

\section{KAYNAKÇA}

CEPNİ, O., KÜÇÜKSARAÇ, D. \& YILMAZ, M.H. (2017). The sensitivity of credit default swap premium to global risk factor: Evidence from emerging markets, Economics Letters, 159, 74-77.

CLARK, E. \& KASSIMATIS, K. (2015). Macroeconomic effects on emergingmarkets sovereign credit spreads, spreads, Journal of Financial Stability, 20, 1-13.

ENDERS, W. \& LEE, J. (2012). The flexible Fourier form and the Dickey-Fuller type unit root tests, Economics Letters, 117, 196-199.

ENDERS, W. \& JONES, P. (2016). Grain prices, oil prices, and multiple smooth breaks in a VAR", Studies in Nonlinear Dynamics \& Econometrics, 20(4), 399-419.

FILIPPOS, A. (2017). The relationship between CDS spreads and macroeconomic factors of the countries of the Eurozone, Tilburg University, School of Economics and Management, Master's Thesis, August 2017

FONTANA, A. \& SCHEICHER, M. (2010). An analysis of Euro-Area sovereign CDS. European Central Bank Working Paper Series, No:1271, 1-47.

FONTANA, A. \& SCHEICHER, M. (2016). An analysis of Euro-Area sovereign CDS and their relation with government bonds, Journal of Banking \& Finance, 62(C), 126-140. HEINZ, F. F. \& SUN, Y. (2014). Sovereign CDS spreads in Europe - The role of 
Esra N. Kılcı, "Mali Dengeler ile CDS Primleri Arasındaki Nedensellik İlişsisinin Analizine Yönelik Bir Çalışma; Türkiye Örneği", İstanbul Gelişim Üniversitesi Sosyal Bilimler Dergisi, 6 (GELIŞSiM-UWE 2019 Özel Sayısı), Ekim 2019, ss. 59-71.

global risk aversion, economic fundamentals, liquidity and spillovers, IMF Working Paper, WP/14/17, 1-77.

KLIBER, A. (2014). The dynamics of sovereign credit default swaps and the evolution of the financial crisis in selected Central European Economies, Czech Journal of Economics and Finance, 64(4), 330-350.

KOCSIS, Z. \& MONOSTORI, Z. (2016). The role of country-specific fundamentals in sovereign CDS spreads: Eastern European experiences, Emerging Markets Review, 27, 140-168.

LIU, Y. \& MORLEY, B. (2013). Sovereign credit ratings, the macroeconomy and credit default swap spread, Brussels Economic Review, 56(3/4), 335-348.

MELLIOS, C. \& PAGET-BLANC, E. (2006). The impact of macro-economic variables on the sovereign CDS spreads of the Eurozone countries: Examining the determinants of credit default swaps. Journal of Finance, 12(4), 363-382.

METIU, N. (2011). The EMU in debt distress: contagion in sovereign bond market. Research Paper, European Economic Association \& Econometric Society 2011 Parallel Meetings, 25-29 August 2011, Oslo.

NERI, S. \& ROPELE, T. (2015). The macroeconomic effects of the sovereign debt crisis in the Euro Area, Economic Working Papers, 1007, Bank of Italy, Economic Research and International Relations Area ,1-46.

NICKEL, C., ROTHER, P.C. \& RULKE, J. C. (2009). Fiscal variables and bond spreads- Evidence from Eastern European Countries and Turkey, ECB Working Paper Series, No:1101, 1-42.

OLIVEIRA, L., CURTO, D. \& NUNES, P. (2012). The determinants of sovereign credit spread changes in the Euro-zone, Journal of International Financial Markets, Institutions and Money, 22(2), 278-304.

SCHWAAB, B., KOPPMAN, S. J. \& LUCAS, A. (2016). Global credit risk: world, country and industry factors, ECB Working Paper Series, No: 1922, 1-53.

SUNGUR, O. (2015). 2000 sonrası Türkiye ekonomisi: büyüme, enflasyon, işsizlik, borçlanma ve diş ticarette gelişmeler, Toplum ve Demokrasi, 9 (19-20), 243-269.

TCMB (2019). Elektronik Veri Dağıtım Sistemi,

https://evds2.tcmb.gov.tr/index.php?/evds/serieMarket adresinden ulașılmıştır.

TÜİK (2019), Temel İstatistikler,

http://www.tuik.gov.tr/UstMenu.do?metod=temelist adresinden ulaşılmıştır.

YUAN, C. \& PONGSIRI, T. J. (2015). Fiscal austerity, growth prospects, and sovereign CDS spreads: The Eurozone and beyond, International Economics, 141, 50-79.

YÜKSEL, A. \& YÜKSEL, A. (2017). Avrupa borç krizi döneminde global risk faktörleri ve ülke kredi temerrüt takası primi ilişkisi: 19 ülke örneği, Akdeniz I.I.B.F. Dergisi, (36), 1-18.

\section{Summary}

One of the major factors in the debt crisis in Euro-Area experienced over the period of 2010-2014 is the macroeconomic imbalances of the countries under financial stress such as Greece, Spain and Portugal. In the crisis period, the CDS premiums of these countries increased significantly due to the weakening macroeconomic indicators, the deterioration in the global investor perception and the increase in the risk premium. Despite the austerity programs implemented, CDS premiums stayed in high levels for a period. While it is seen that some of the studies focus on the factors that lead to changes in CDS premiums such as stock market, banking sector indicators or political risk, other studies take into consideration some macroeconomic indicators such as economic growth rate, foreign 
Esra N. Kılcı, “Mali Dengeler ile CDS Primleri Arasındaki Nedensellik İlişsisinin Analizine Yönelik Bir Çalışma; Türkiye Örneği", İstanbul Gelișim Üniversitesi Sosyal Bilimler Dergisi, 6 (GELișiM-UWE 2019 Özel Sayısı), Ekim 2019, ss. 59-71.

exchange rates, interest rates, current account deficit, inflation, unemployment and fiscal balances. The weakening in macroeconomic outlook and fiscal balances lead to deterioration in investor risk perception and sovereign risk premiums. Therefore, in particular, the issue regarding the impact of financial indicators on bond margins and CDS premiums is considered highly important for researchers, policy makers and foreign investors since the Euro-Area debt crisis experienced in 2010-2014.

Most researchers such as Nickel et al (2009), Oliverira et al (2012), Clark and Kassimatis (2015), Schwaab et al (2016), emhasize in their studies that financial markets have severely penalized the financial and macroeconomic imbalances of the countries and that their interactions with international risk factors have been priced in Euro-Area debt crisis. The deterioration in macroeconomic fundamentals, high budget deficits and current account deficits were priced in financial markets and also led to significant increases in the sovereign bond spreads and CDS premiums. As it is obviously seen in 2010-2014 Euro-Area debt crisis, excessive fiscal imbalances and high debt levels lead to increase in fragility in financial markets of the countries.

In the period after the 2001 Economic Crisis experienced in Turkey, it has been seen a positive trend in macro-financial indicators thanks to the fiscal discipline and structural reforms. Furthermore, in addition to the positive developments in inflation and economic growth, the budget deficit and the public debt to GDP ratios have been below the maximum limits set by the Maastricht Criteria. The objective of this study to investigate the relationship between fiscal balances as budget deficit to GDP ratio and current account deficit to GDP ratio and sovereign CDS premiums in the period of 2006:Q1-2018:Q3. In the analysis, Fourier ADF unit root test and Fourier Granger causality test are employed by using the quarterly data obtained from TurkSTAT Statistics Database and Bloomberg. In the analysis, the results appear to differ significantly from the results in the past, when the Fourier terms are used in the process of controlling structural breaks. These test allow for taking into account multiple structural breaks in the analysis, contributing to credibility of the results. The findings of the analysis support the causality relationship from current account to GDP ratio to sovereign CDS premiums for the period of 2006:Q1-2018:Q3 in Turkey. Accordingly, it is seen that current account deficit to GDP ratio, one of the indicators of fiscal balances, has impact on CDS premiums in the relevant period.

It is emphasized in the academic literature that current account deficits do not seem problematic for emerging market economies as long as capital inflows continue. On the other hand, it is seen that high current account deficits are financed by external borrowing and capital inflows in the form of portfolio investments in these economies. In these emerging market economies including Turkey, the high current account deficits lead to problems for the economies due to the reasons such as increasing uncertainty, rising financing costs and adverse capital flows in times of increasing financial stress because of the increasing external borrowing costs and the debt roll-over problems. At the same time, foreign investors prefer to move their portfolio investments to safe heaven economies when financial stress increases. Therefore, it is very important to monitor the policies to take under control the current account deficit in these economies. Considering the causality relationship found in the emprical analysis from the current account deficit to GDP ratio to CDS premiums, it is concluded that the improvement in the current account deficit will have a positive effect on CDS premiums, which indicate that the default risk and borrowing costs have increased. Finally, the improvements in the current account deficit with the solutions as austerity practises and measures to ensure fiscal balance have positive impact on CDS premiums by contributing to the strenghtening of the country's macro-financial outlook. 